\title{
Damage analysis of CFRP under impact fatigue
}

\author{
George Tsigkourakos*, Vadim V. Silberschmidt and Ian A. Ashcroft \\ Wolfson School of Mechanical and Manufacturing Engineering, Loughborough University, Leicester-shire, LE11 \\ $3 T U, U K$
}

Received 24 February 2010

Revised 6 October 2010

\begin{abstract}
In recent years carbon fibre reinforced polymers (CFRPs) have become some of the most important structural materials in the aerospace industry due to their excellent stiffness and strength to weight ratios. The real-life loading histories of aerospace composite components and structures involve the generation of transient loads that can propagate as cyclic impacts. This phenomenon is known as impact fatigue (IF). Such loads can cause various types of damage in composites, including fibre breakage, transverse matrix cracking, de-bonding between fibres and matrix and delamination, resulting in a reduction of residual stiffness and a loss of functionality.

The effects of IF are of major importance due its detrimental effect on the performance and reliability of components and structures after relatively few impacts and low force levels compared to those in a standard fatigue regime. This study employs a unique testing system with the capability of subjecting specimens to fully instrumented repetitive impact loading. The main aim of this paper is to provide results elucidating the effect of IF on the damage behaviour of CFRP specimens. A detailed damage analysis is implemented utilising an X-ray micro computed tomography (CT) system.
\end{abstract}

Keywords: Impact fatigue, micro CT, CFRP, cracks

\section{Abbreviations}

$\begin{array}{ll}\text { Symbol } & \text { Meaning } \\ \text { CFRP } & \text { Carbon fibre reinforced polymer } \\ \text { IF } & \text { Impact fatigue } \\ \text { Nf } & \text { Number of cycles to failure under IF } \\ \text { UD } & \text { Unidirectional } \\ \text { NDT } & \text { Non-destructive technique } \\ \text { Micro-CT } & \text { Micro computed tomography } \\ \text { ROI } & \text { Region of interest } \\ \text { FEM } & \text { Finite Element Modelling }\end{array}$

${ }^{*}$ Corresponding author: Ashby Road, Loughborough, Leics., LE11 3TU, UK. Tel.: +44 1509 227504; Fax: +44 1509 227502; E-mail: G.Tsigkourakos@lboro.ac.uk. 
Table 1

Properties of 8552 matrix at room temperature (Hexply Corporations data sheet)

\begin{tabular}{ll}
\hline Glass transition temperature $\operatorname{Tg}\left({ }^{\circ} \mathrm{C}\right)$ & 200 \\
Cured density $\rho\left(\mathrm{g} / \mathrm{cm}^{3}\right)$ & 1.3 \\
Tensile strength $(\mathrm{MPa})$ & 121 \\
Elongation at failure $(\%)$ & 1.7 \\
Tensile modulus $(\mathrm{GPa})$ & 4.67 \\
\hline
\end{tabular}

\section{Introduction}

The use of carbon fibre reinforced polymers (CFRPs) in the aerospace and other high technology industries has increased enormously in the last few decades and looks set for significant further expansion. This has been largely because of the high specific stiffness and strength of these materials, however, other properties such as fatigue resistance, property tailoring and manufacturing flexibility may also be of significance in certain applications. The result is that CFRPs are now one of the most important structural materials in the aerospace industry.

CFRP structures in aerospace, and other, structural applications are generally subjected to some form of cycling loading, i.e. fatigue. In the laboratory, fatigue is generally approximated as a sinusoidally varying load or stress, characterised by the load ratio, frequency and maximum force. This type of loading can be termed standard fatigue (SF). However, real-life loading histories often involve vibrating loads that can propagate in structural elements as cyclic impacts. This phenomenon is known as impact fatigue (IF) [1]. IF is of major importance to the structural integrity of components and structures due to its detrimental effect on performance, which can occur after a relatively small number of low amplitude cycles [1,2].

Fatigue loading can cause various types of damage in laminate composites; eg. fibre breakage, transverse matrix cracking, de-bonding between fibres and matrix and delamination, resulting in a reduction of the residual stiffness and a loss of functionality [3-5]. Furthermore, the damage in composites is often subsurface and non-destructive techniques (NDT) such as X-ray Micro-CT scanning are required for characterisation of the internal geometry of flaws. X-ray Micro-CT has been applied to metal-matrix [6-11], ceramic-matrix composites [12] and polymer matrix composites [13-16]. The purpose of the current study is to analyze the capabilities and limitations of X-ray micro-CT for the characterization of impact damage induced by the Izod testing of CFRP.

\section{Experimental details}

\subsection{Materials and sample manufacture}

The specimens used in this work were made from IM7/8552 unidirectional (UD) CFRP, supplied by Hexcel Corp., Duxford, UK. The matrix, HexPly 8552, is an amine cured toughened epoxy material, the properties of which are shown in Table 1. The carbon fibre used as reinforcement in the composite is the intermediate-modulus fibre HexTow IM7. UD pre-preg material with a nominal fibre volume fraction of 0.6 and thickness of $0.125 \mathrm{~mm}$ was laid up in a 16-ply stacking arrangement. The final plate dimensions were $400 \mathrm{~mm} \times 400 \mathrm{~mm}$ and the thickness of the cured plates was approximately $2 \mathrm{~mm}$.

The plates were cured for 2 hours at $182^{\circ} \mathrm{C}$, with an initial autoclave pressure of approximately $700 \mathrm{kPa}$. Material data for UD IM7/8552 from the Hexcel product data sheet is shown in Table 2.

\subsection{Izod test}

Izod is a single impact test used to measure the impact resistance of a material. In an Izod impact test the reduction in kinetic energy of a swinging pendulum is equated to the energy required to completely break a notched sample of standard dimensions. The Izod specimens are notched to limit plastic deformation of the specimen upon impact. Testing involves a specimen clamped into the test fixture with the notched side facing the striking edge of the pendulum as shown in Fig. 1(a). The pendulum is released and allowed to strike through the specimen. The impact strength is expressed in $\mathrm{kJ} / \mathrm{m}^{2}$. The higher the resulting number, the tougher the material. 
Table 2

Properties of IM7/8552 composite at room temperature (Hexply Corporations data sheet)

\begin{tabular}{lc}
\hline$E_{11 T}(\mathrm{GPa})$ & 165 \\
$E_{22 T}(\mathrm{GPa})$ & 11.38 \\
$E_{33 T}(\mathrm{GPa})$ & 11.38 \\
$G_{12}(\mathrm{GPa})$ & 5.12 \\
$G_{23}(\mathrm{GPa})$ & 5.12 \\
$G_{13}(\mathrm{GPa})$ & 3.92 \\
$v_{12}$ & 0.3 \\
$v_{23}$ & 0.487 \\
$v_{13}$ & 0.3 \\
$\mathrm{~S} 11_{T}(\mathrm{GPa})$ & 2.6 \\
$\mathrm{~S} 11_{C}(\mathrm{GPa})$ & 1.5 \\
$\mathrm{~S} 22_{T}(\mathrm{MPa})$ & 60 \\
$\mathrm{~S} 22_{C}(\mathrm{MPa})$ & 290 \\
$\mathrm{Ss}(\mathrm{MPa})$ & 90 \\
\hline
\end{tabular}

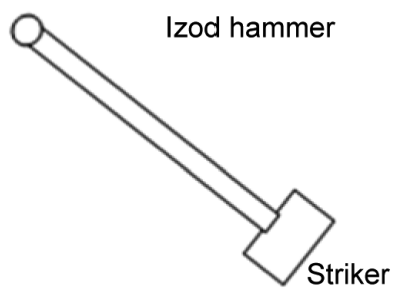

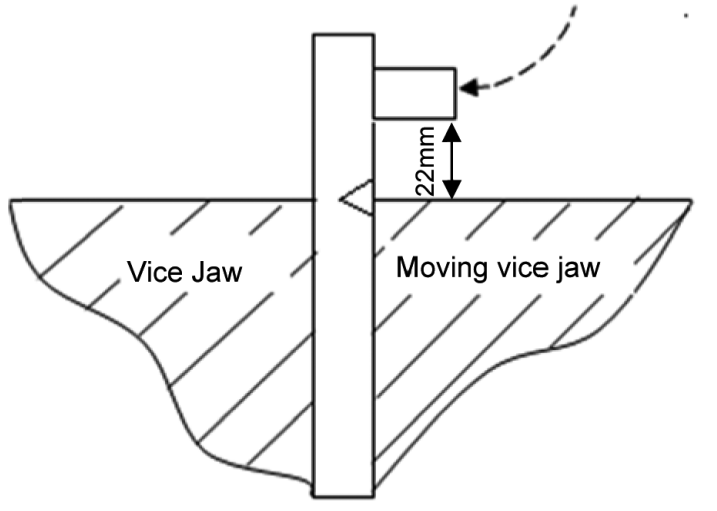

(a)

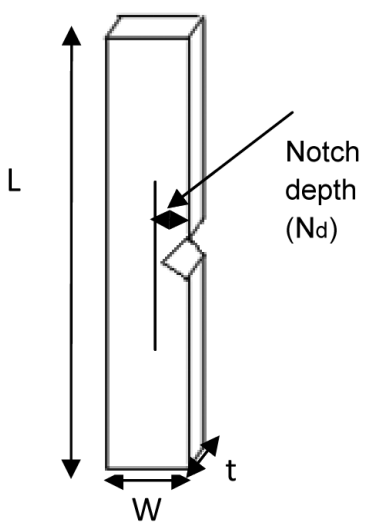

(b)

Fig. 1. (a) Impact test set-up indicating the position of the specimen in the vice, the motion of the Izod hammer and the impact point. (b) Schematic of the specimen used in Izod tests where $\mathrm{L}$ is the length, $\mathrm{W}$ is the width and $\mathrm{t}$ is the thickness.

Izod specimens were cut from the UD CFRP material described above using a milling machine. The specimen configuration is displayed in Fig. 1 (b) where length, L, was $80 \mathrm{~mm}$, width, W, was $10 \mathrm{~mm}$ and thickness t was $1 \mathrm{~mm}$ or $4 \mathrm{~mm}$. The samples were notched using a single-tooth carbide cutter. Notches of 2 and $6 \mathrm{~mm}$ depth were cut into the $1 \mathrm{~mm}$ thick specimens ( 8 in total) and $4 \mathrm{~mm}$ thick (16 in total) specimens respectively. The two sets of samples were termed Group A and B, as detailed in Table 3. According to British standard (BS EN ISO 180:1996) composite samples must have a 45 degree $\mathrm{V}$ notch in the middle of the sample length and the hammer must strike $22 \mathrm{~mm}$ above the notch, as shown in Fig. 1(a). The samples made for this test were notched with a slow cutter speed, fast feed rate and the use of coolant in order to avoid thermal damage i.e raising the temperature of the matrix above its glass transition temperature.

In a standard Izod test the pendulum is given enough kinetic energy to completely break the sample, as described earlier. However, when conducting impact-fatigue tests, an initial kinetic energy significantly below that required to 
Table 3

Specimen configurations all dimensions in $\mathrm{mm}$

\begin{tabular}{lcccc}
\hline & Width (W) & Length $(\mathrm{L})$ & Thickness $(\mathrm{t})$ & Notch depth $(\mathrm{Nd})$ \\
\hline GROUP A & 10 & 80 & 1 & 2 \\
GROUP B & 10 & 80 & 4 & 6 \\
\hline
\end{tabular}

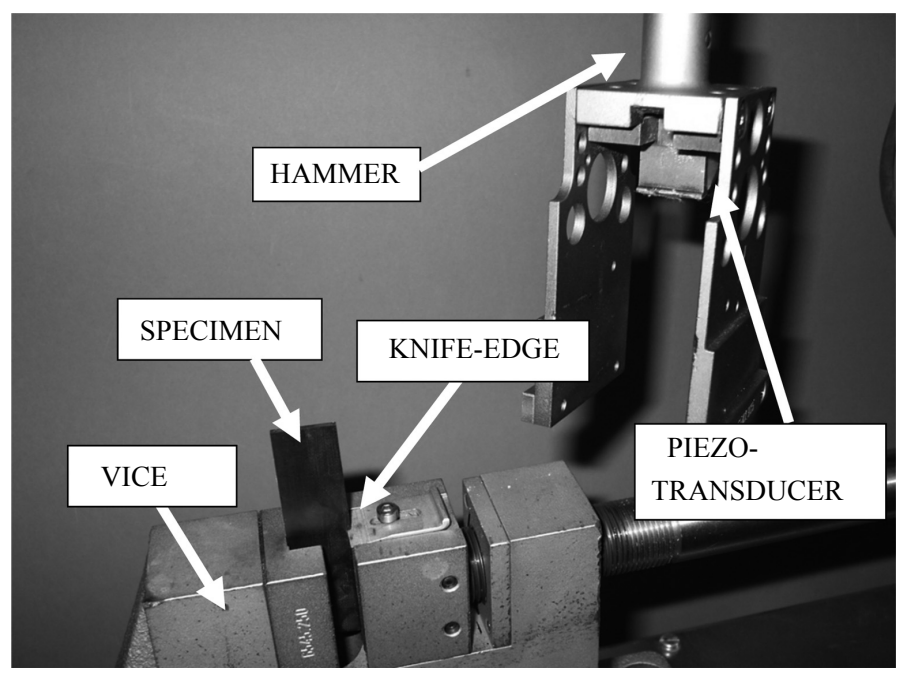

Fig. 2. Izod test configuration during testing.

cause complete failure in a single impact test must be used. In this work a calibrated impact hammer with mass of $0.334 \mathrm{~kg}$ and nominal length of $0.3268 \mathrm{~m}$ was used. The pendulum hammer was released from a pre-selected initial angle in the range of $0-150^{\circ}$ which corresponds to a potential energy in the range of $0-2 \mathrm{~J}$ and velocity between 0-3.46 m/s. The impact-fatigue tests were carried out using a modified CEAST Resil impactor, which is shown in Fig. 2. The specimen is supported at one end by an instrumented vice and its opposite end is struck repeatedly by a controlled pendulum hammer, with the hammer being caught and returned to the same starting position after each impact. The impact of the pendulum hammer produces a tensile load in the specimen over a period of 6-7 ms and the period between the impacts is approximately $15 \mathrm{~s}$. The evolution of force, displacement and the energy during each impact can be monitored at $5 \mu$ s intervals and up to 8000 points can be stored for each impact. In order to decrease the data noise a $1 \mathrm{KHz}$ filter can be used. The amplified and filtered data is downloaded to a computer as magnitudes of force and time and this data is then used to calculate velocity, $\mathrm{V}$, displacement, $\mathrm{d}$, and absorbed energy, E, for each impact, as indicated in Fig. 3(a). Figure 3(b) shows a typical force time plot indicating the loading time, $\mathrm{T}_{F}$, which is defined as the time interval between the initial loading point and the moment that the applied force diminishes to zero.

\subsection{Izod tests results}

Impact tests were conducted in energy control which means that the applied force is not a directly controllable variable. Impact damage can be characterised by a decrease in impact energy (E) with number of cycles required to failure (Nf) [2]. An E vs Nf plot for both $4 \mathrm{~mm}$ and $1 \mathrm{~mm}$ thick samples is presented in Fig. 4 . The figure demonstrates a similar trend in the data for the first and second groups of specimens in that there is an approximately linear relationship between $\mathrm{E}$ and $\log (\mathrm{Nf})$. As explained, the impact energy associated with a given $\mathrm{Nf}$ is significantly lower for the $1 \mathrm{~mm}$ thick samples than for the $4 \mathrm{~mm}$ thick samples, the ratio in impact energy being approximately the same as the thickness ratio. A level of scatter is apparent in Fig. 4, however, this is inevitable as fatigue is a probabilistic phenomenon.

The results in this section have shown that CFRP's are susceptible to rapid degradation and failure when subject to IF. It is also seen that IF can be studied E- Nf graphs. These graphs show that as the impact energy decreases, 


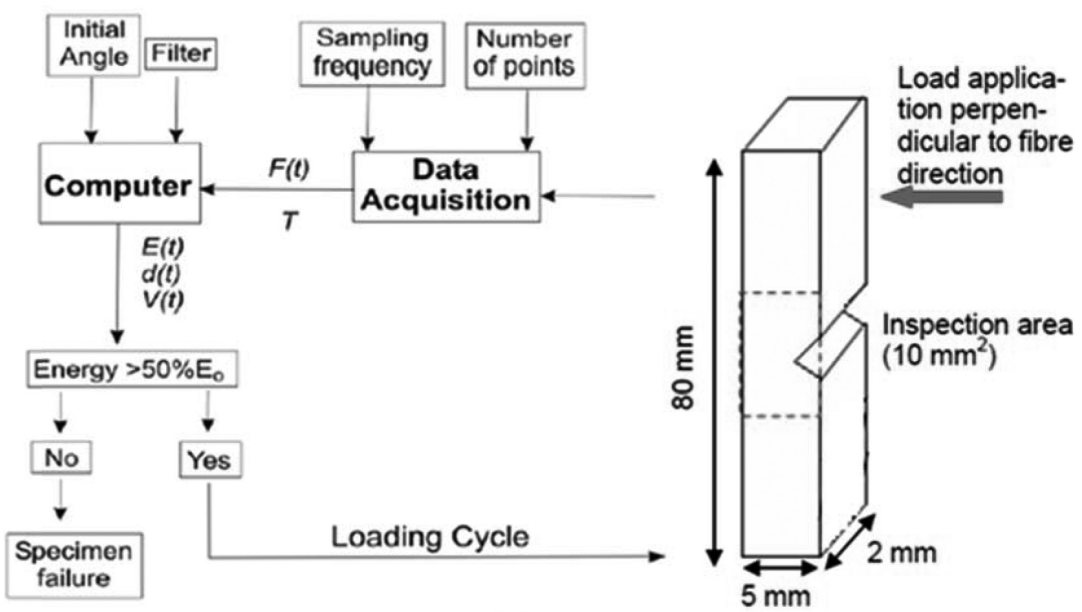

(a)

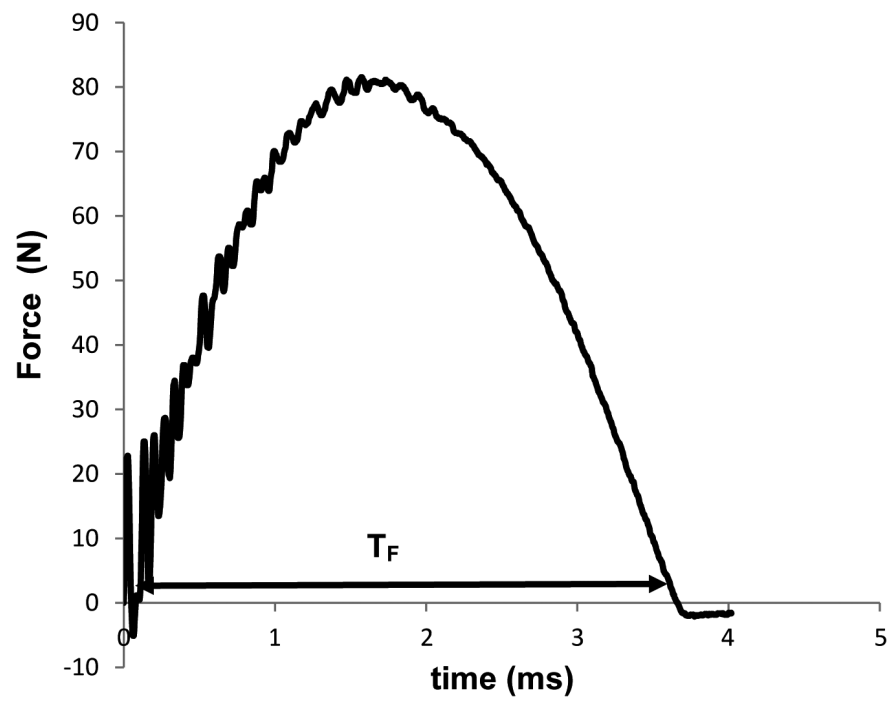

(b)

Fig. 3. (a) Izod test specimen during testing at energy of $0.02 \mathrm{~J}$ and (b) force data acquisition indicating the loading time $\mathrm{T}_{F}$.

the number of cycles to failure will increase in a quasi-linear fashion. From the data that had been tested it is seen that in cases of IF a fatigue limit is not clearly observable, making this a potential problem in designing against IF. Analysis of damaged surfaces during the subjection to IF is required to reveal the phenomenon in the micro-level. This will take place in the following section.

\section{X-ray microtomography}

\subsection{Introduction}

X-ray micro-CT measurements were performed using an XT H 225 X-ray and CT inspection system that was purchased by X-Tek Group. The system consists of on a 1-dimensional X-ray detector and an electronic X-ray source, creating 2-dimensional images of the object. The source is a sealed X-ray tube operating at $25-225 \mathrm{kV}$ with a 


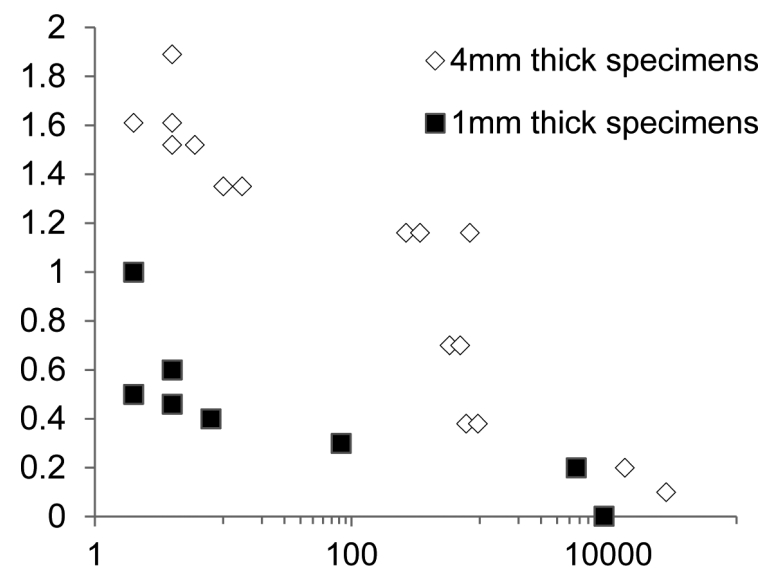

Fig. 4. Impact energy (E) vs number of of impacts to failure (Nf) during IF in semi-logarithmic coordinates.

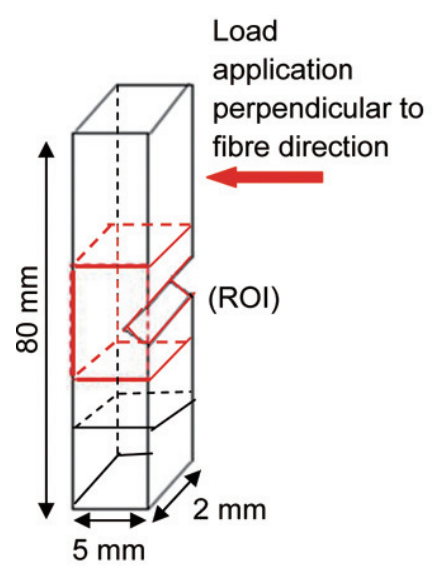

(a)
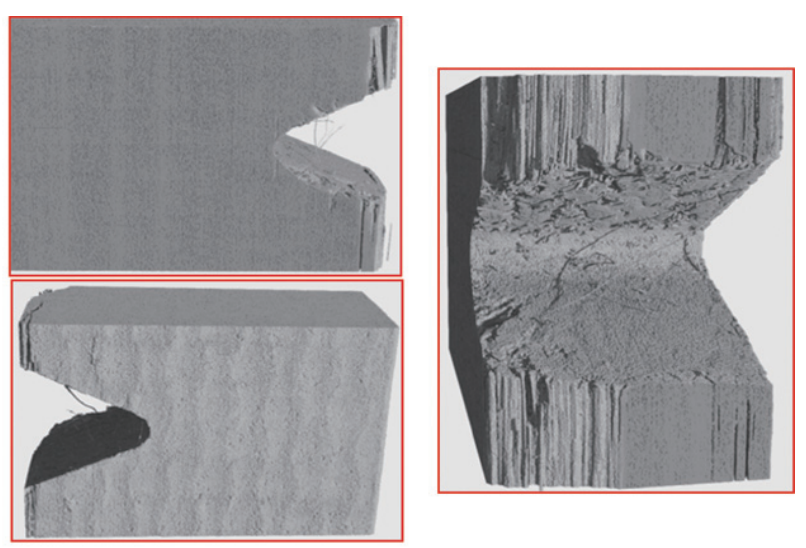

(b)

Fig. 5. (a) Specimen schematic highlighting the region of interest (ROI), (b) Side views and front view of the ROI.

$3 \mu \mathrm{m}$ spotsize. Data for the studied composite were collected at $60 \mathrm{kV}$ and $80 \mu \mathrm{A}$. An object manipulator, with two translations and one rotation, facilitates, rotating the sample for acquisition of tomographic data, raising/lowering the sample to select a region of interest, and translating along the optical axis to adjust the magnification.

For 3-D reconstruction, transmission X-ray images were acquired from 3600 rotation views over $360^{\circ}$ of rotation $\left(0.1^{\circ}\right.$ rotation step $)$. Following acquisition a precise software program builds a $3 \mathrm{D}$ volume dataset by 'stacking' the individual slices one on top of the other. The program is capable of displaying the volume in an alternative manner. It has to be noted that a special specimen was made since as for accurate resolution of microcracks the width of the specimen should be limited to $5 \mathrm{~mm}$ width. Furthermore this specimen was notched at $1 \mathrm{~mm}$ while the length and thickness was kept the same as Group A Table 3. Finally it was subjected to 250,400 and 600 impacts of 0.02 Joules. It has to be noted that after every group of impacts $(250,400$ and 600$)$ the specimen was removed and examined in the X-ray microCT apparatus.

\subsection{Results and discussion}

Damage in the UD IM7/8552 composites generated in the IF Izod tests was studied. The findings illustrate the capabilities of the micro-CT system and the evolution of the damage with IF cycles. The main CT scanning and reconstruction parameters were the pixel size, which was $3.5 \mu \mathrm{m}$ and the exposure time that was kept at $1 \mathrm{~s}$. Figure 5a presents the dimensions of the specimen as well as the region of interest (ROI) selected for analysis. In Fig. 5b 


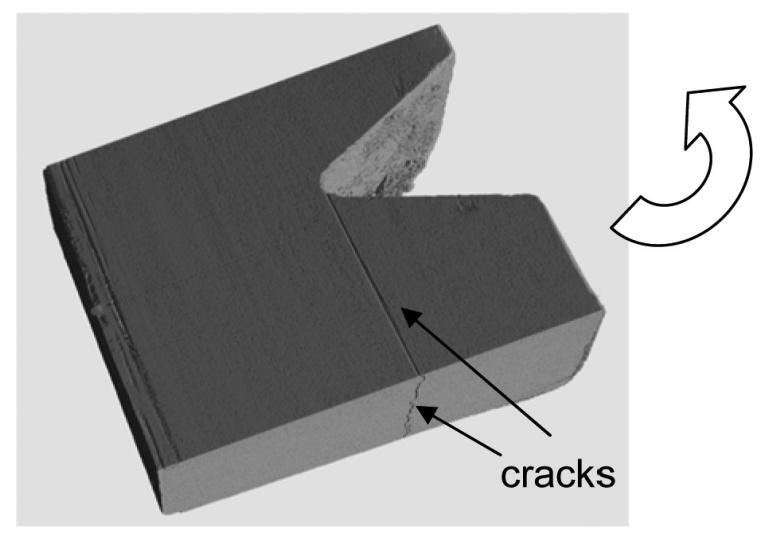

Fig. 6. Damaged bottom area or region of interest and arrow indicating how the view was rotated in order to emphasise at the whole crack distribution.

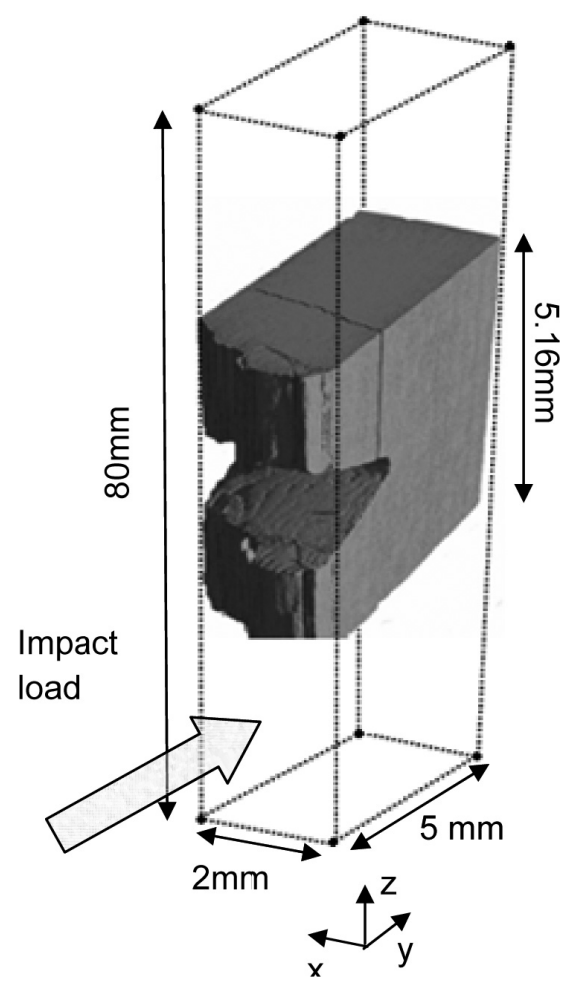

Fig. 7. Inverted view of the region of interest and schematic of the volume of the examined area in comparison with the actual specimen volume.

the side and front views of the undamaged specimen are presented. Signs of matrix cracking and fibre pullout are visible at the edges due to formation of the notch (front view Fig. 5); the cutting plane was perpendicular to the fibre direction. After 250 impacts the specimen was removed from the IF machine and was re-examined. A through thickness can be seen Fig. 6. In order to observe the full extent of the damage shown in Fig. 6, the view is inverted to the orientation illustrated in Fig. 7.

Figures 8 to 12 shows the comparison between undamaged and damaged states of the tested specimen. A crack can be seen to be growing substantially in the fibre direction and across the sample width. The transition from one side of the specimen to the other can been seen more clearly in Figs 10, 12. In Fig. 11 it can be observed that the crack initially as the root of the notch at one side grows almost parallel to the notch tip in the $\mathrm{x}$ direction whilst also 

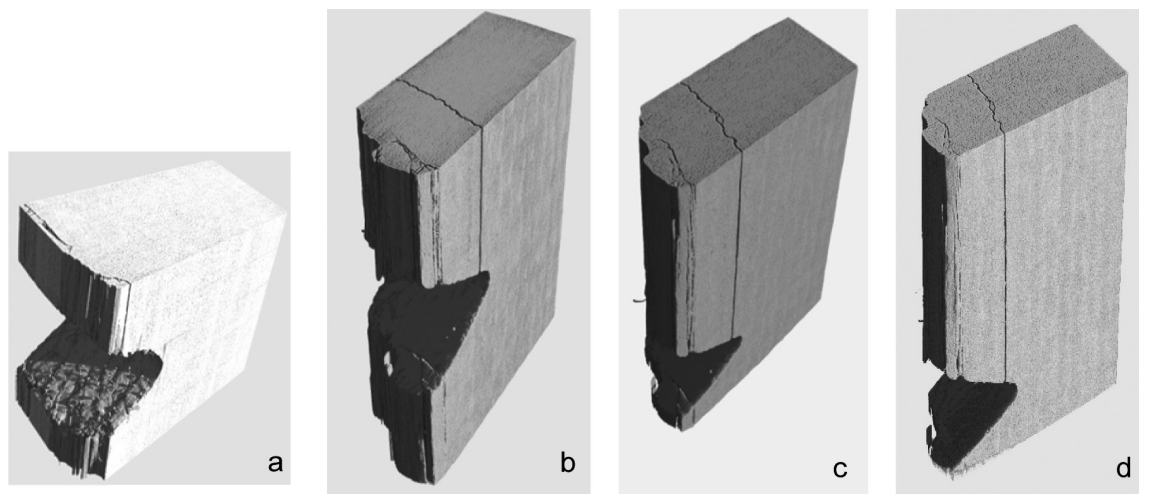

Fig. 8. Right-side view before testing (a); after 250 impacts (b); after 400 impacts and after 600 impacts (d)
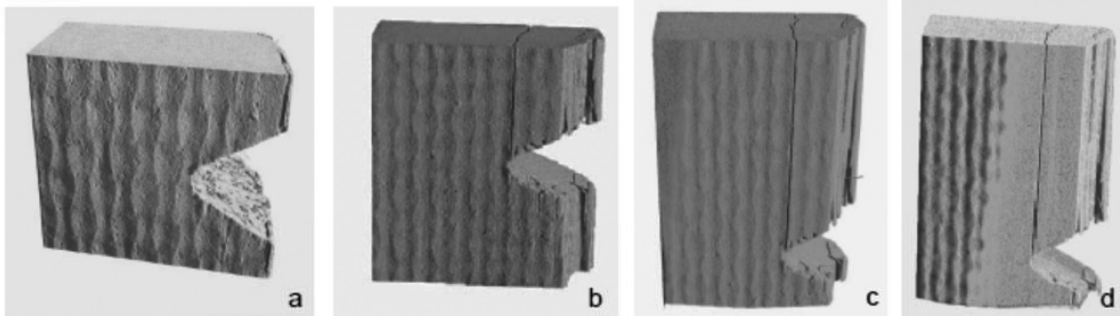

Fig. 9. Left-side view before testing (a); after 250 impacts (b); after 400 impacts and after 600 impacts (d).
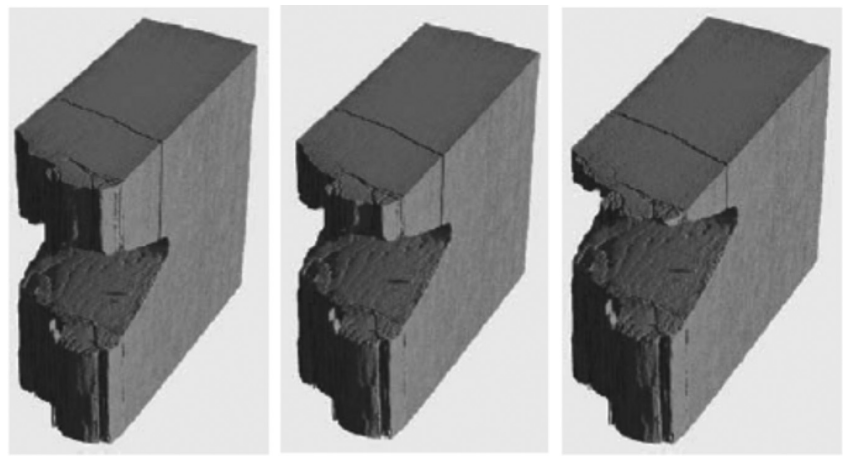

Fig. 10. Views for successive sectioning along the $\mathrm{z}$ axis at 3 intervals of $0.5 \mathrm{~mm}$ (after 250 impacts).

grows in the z-direction.The damge in the y-direction is illustrated in Fig. 12 that showssuccesive sections along this axis. The most important failure mechanism in composites that is responsible for strength deterioration of a laminate are matrix cracks and delamination. While fibre failure is the ultimate failure mechanism, matrix cracks and delaminations can occur much earlier.

Since in the case of a UD composite we deal with only one ply ( This assumption lies in the fact that delamination occurs due to stiffness diferrence between differently oriented plies) it is reasonable to categorise the damage as intralaminar, i.e internal within the ply. This means that the cracks present after impact are due to matrix cracking and probably, breaking of few fibres. Furthermore, the type of damage can be categorised as Mode II (in plane shear) due to the nature of loading. Moreover, it can be said that fibres act as impact wave guides since matrix cracks are propagating initially along the length of the fibres.

After presenting the capabilities of Micro-CT in visualising the crack propagation after a series of impacts it is important to quantify this damage. Micro-CT is capable of providing information about the total volume/area of the 

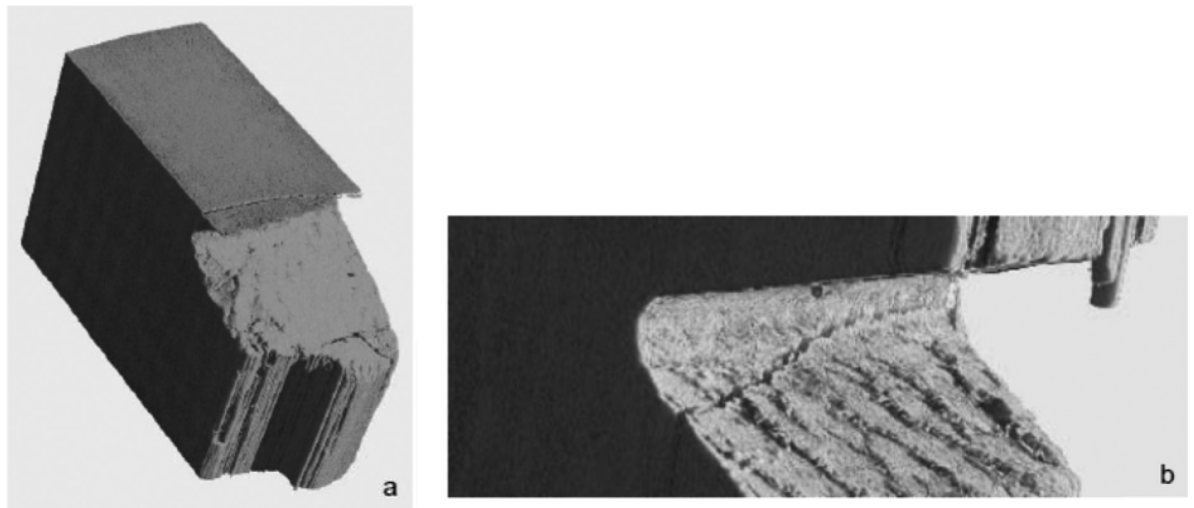

Fig. 11. Side view indicating the relative positioning of crack (a) and notch and crack intersection with the notch (b).
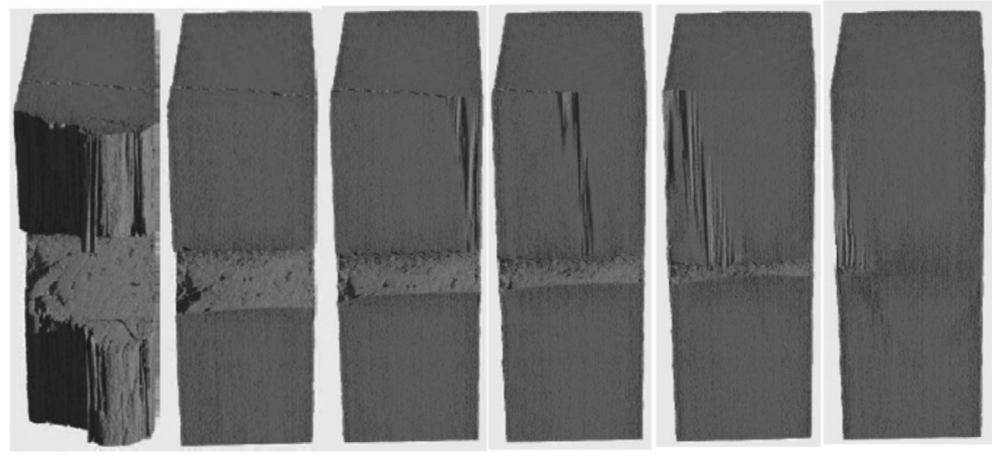

Fig. 12. Views of successive sectioning at 5 intervals of $0.2 \mathrm{~mm}$ along the y axis after 250 impacts (Note that the notch depth is $1 \mathrm{~mm}$ ).

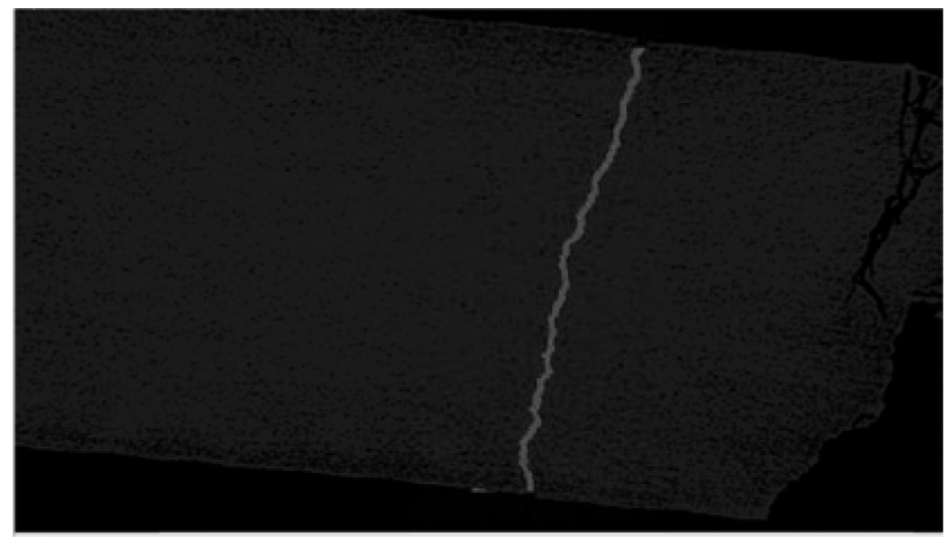

Fig. 13. Specimen top view highlighting the capabilities of the region growing algorithm to isolate the crack area.

cracks using a region growing algorithm. This enables quantification of delamination area or the crack distribution. Figures 13 to 15 present this procedure. Initially a region of interest is selected in each direction (Figs 13 and 14). Then the whole 3-D profile is constructed as shown in Fig. 15 and is 'filled' with the region growing algorithm (grey area). After 'filling' the region of interest, information about the volume/area of the cracks can be obtained by the histogram of the region based on the grey level distribution. In our case the total area measured was $3 \mu \mathrm{m}^{2}$. 


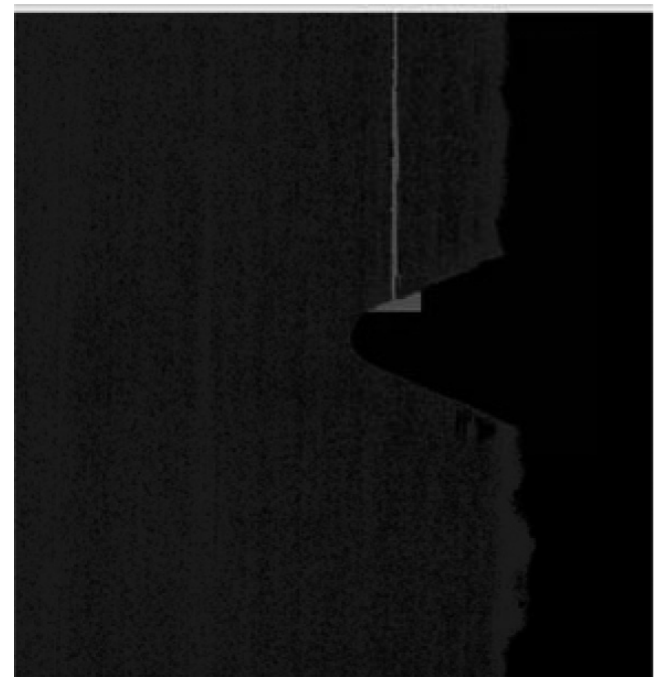

Fig. 14. Specimen side view highlighting the capabilities of the region growing algorithm to isolate the crck area.

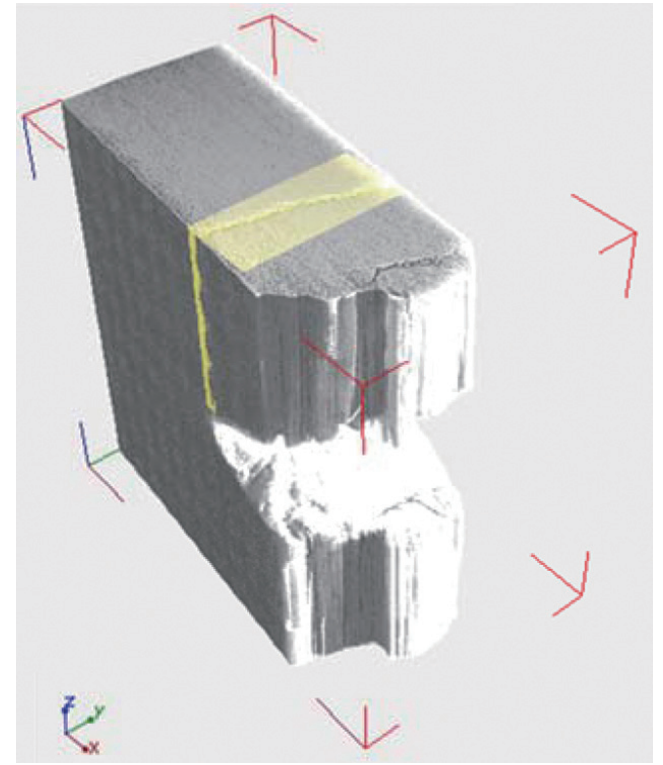

Fig. 15. Specimen 3-D view highlighting the capabilities of the region growing algorithm to isolate the crack volume.

\section{Conclusions}

The findings of this research indicate that X-ray microtomography can facilitate characterization of microcracking, in CFRP's. The most important observations can be highlighted as follows:

- For the sufficient resolution of defects the sample width is limited to $5 \mathrm{~mm}$.

- Cracks in the UD specimens grow from the notch to the area furthest away from the impact point in a quasi-2-D fashion and fibres act as waveguides.

- A region growing algorithm can be used to characterise damage by measuring the area of cracks. 


\section{Notation}

$\begin{array}{ll}\text { Symbol } & \text { Meaning } \\ V & \text { Velocity } \\ d & \text { Displacement } \\ E & \text { Impact energy } \\ \mathrm{Tg} & \text { Glass transition temperature } \\ \rho & \text { Cured density } \\ E 11 T & \text { X longitudinal Young modulus } \\ E 22 T & \text { Y longitudinal Young modulus } \\ E 33 T & \text { Z longitudinal Young modulus } \\ G 12 & \text { Shear modulus 12 } \\ G 23 & \text { Shear modulus 23 } \\ G 13 & \text { Shear modulus 13 } \\ v 12 & \text { Poisson's ratio that corresponds to a contraction in the direction } 2 \text { when an extension is applied in } \\ & \text { direction 1 } \\ v 23 & \text { Poisson's ratio that corresponds to a contraction in the direction } 3 \text { when an extension is applied in } \\ & \text { direction 2 } \\ v 13 & \text { Poisson's ratio that corresponds to a contraction in the direction } 3 \text { when an extension is applied in } \\ & \text { direction 1 } \\ S 11 T & \text { Longitudinal tensile strength } \\ S 11 C & \text { Longitudinal compressive strength } \\ S 22 T & \text { Transverse tensile strength } \\ S 22 C & \text { Transverse compressive strength } \\ S s & \text { Shear strength }\end{array}$

\section{References}

[1] J.P. Casas-Rodriguez, I.A. Ashcroft and V.V. Silberschmidt, Damage evolution in adhesive joints subjected to impact fatigue, J Sound Vib 308 (2007), 467-478.

[2] J.P Casas-Rodriquez, I.A.Ashcroft and V.V.Silberschmidt, Damage in adhesively bonded CFRP joints: sinusoidal and impact fatigue, Comp Sci Tech 68 (2008), 2663-2670.

[3] I.A. Ashcroft, J.P. Casas-Rodriguez and V.V. Silberschmidt, Mixed mode crack growth in bonded composite joints under standard and impact fatigue loading, J Mat Sci 43 (2008), 6704-6713.

[4] T. Sınmazçelik, A.A. Arıcı and V. Günay, Impact-fatigue behaviour of unidirectional carbon fibre reinforced polyetherimide (PEI) composites, Mater Sci 41 (2006), 6237-6244.

[5] M.Ö. Bora, O. Çoban, T. Sinmazçelik, I. Cürgül and V. Günay, On the life time prediction of repeatedly impacted thermoplastic matrix composites, Materials \& Design 30 (2009), 145-153.

[6] E. Maire, L. Babout, J.Y. Buffiere and R. Fougeres, Recent results on 3D characterisation of microstructure and damage of metal-matrix composites and a metallic foam using X-ray tomography, Mat Sci Eng A-Struct 319 (2001), 216-219.

[7] S.A. Mcdonald, M. Preuss, E. Maire, J.Y. Buffiere, P.M. Mummery and P.J. Withers, X-ray tomographic imaging of Ti/SiC composites, $J$ Micros - Oxford 209(Part 2) (2003), 102-112.

[8] P.M. Mummery, B. Derby, P. Anderson, G.R. Davis and J.C. Elliot, X-ray mictrotomographic studies of metal-matrix composites using laboratory X-ray sources, J Micros 177 (1995), 399-406.

[9] A. Borbély, H. Biermann, O. Hartmann and J.Y. Buffiere, The influence of the free surface on the fracture of alumina particles in an Al-A12O3 metal-matrix composite, Comp Mater Sci 26 (2003), 183-188.

[10] L. Babout, W. Ludwig, E. Maire and J.Y. Buffiere, Damage assessment in metallic structural materials using high resolution synchrotron X-ray tomography, Nucl Instrum Meth B 200 (2003), 303-307.

[11] I. Justice, P. Anderson, G. Davis, B. Derby and J. Elliot, Damage nucleation and growth in particle rein-forced aluminium matrix composites, Key Eng Mat 127-131 (1997), 945-952.

[12] G. Geandier, A. Hazotte, S. Denis, A. Mocellin and E. Maire, Microstructural analysis of alumina chromium composites by X-ray tomography and 3-D finite element simulation of thermal stresses, Scripta Mater 48 (2003), 1219-1224.

[13] O. Çoban O, M.Ö. Bora, T. Sinmazçelik, I. Cürgül and V. Günay, Fracture morphology and deformation characteristics of repeatedly impacted thermoplastic matrix composites, Materials \& Design 30 (2009), 628-634.

[14] D.D. Symons, Characterisation of indentation damage in 0/90 lay-up T300/914 CFRP, Compos Sci Technol 60 (2000), $391-401$. 
[15] J.P. Dunkers, D.P. Sanders, D.L. Hunston, M.J. Everett and W.H. Green, Comparison of optical coherence tomography, X-ray computed tomography, and confocal microscopy results from an impact damaged epoxy/E-glass composite, J Adhesion 78 (2002), 129-154.

[16] R.H. Bossi and G.E. Georgeson, Composite structure development decisions using X-ray CT measurements, Mater Eval (1995), 1198-1203. 

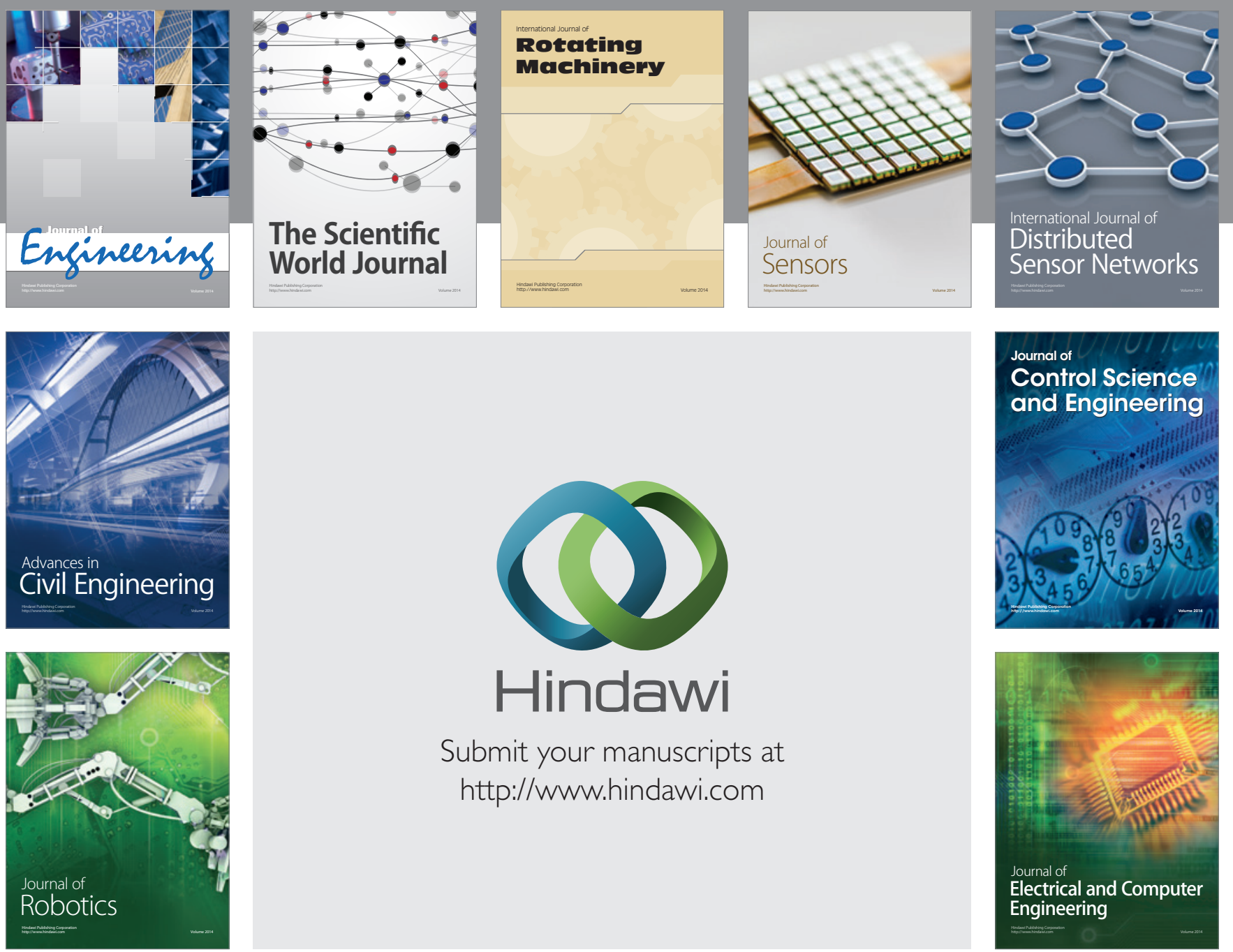

Submit your manuscripts at

http://www.hindawi.com
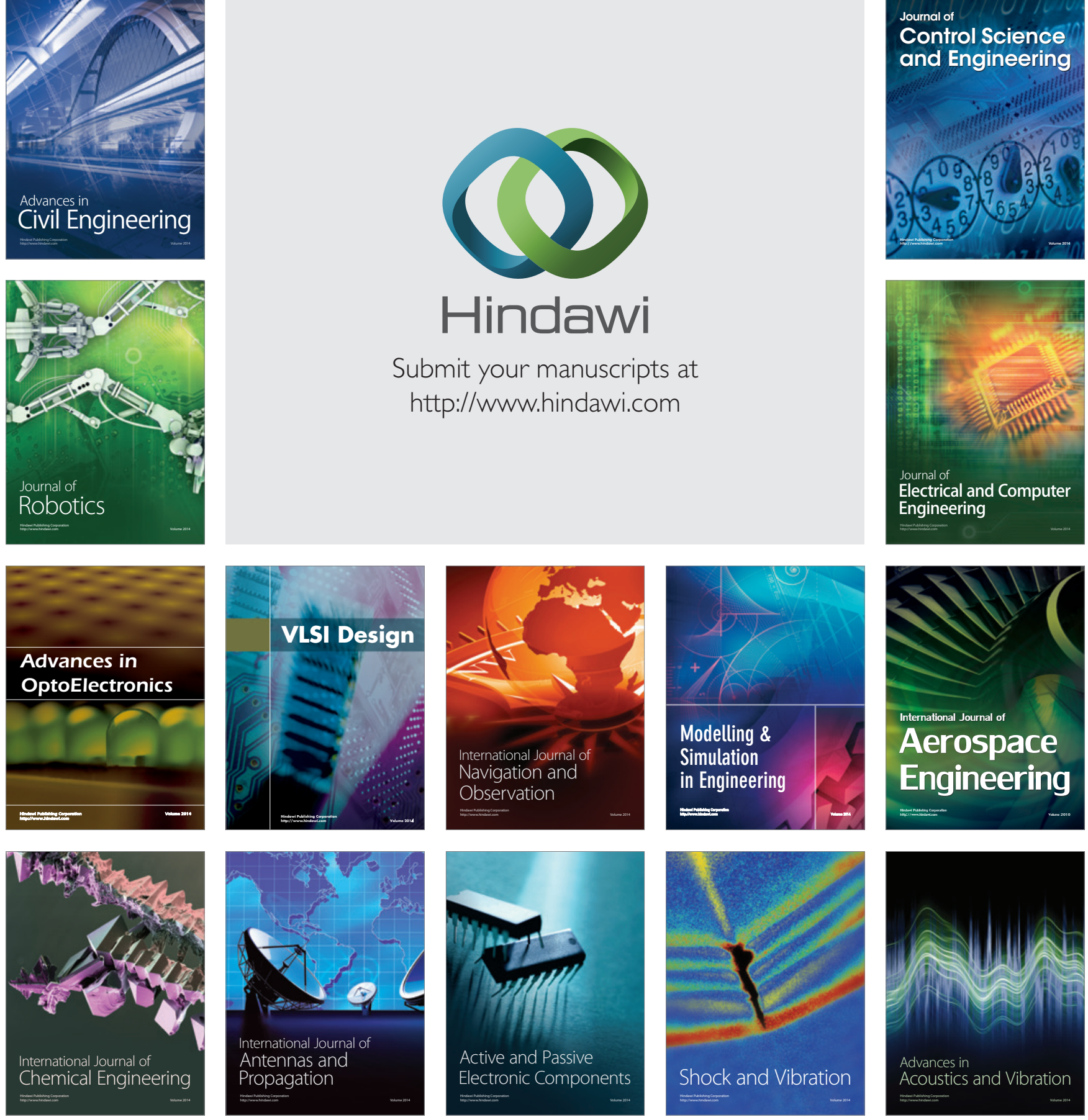